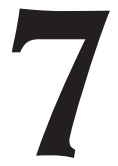

\title{
SMARTPHONES: READING HABITS AND OVERUSE. A QUALITATIVE STUDY IN DENMARK, LITHUANIA AND SPAIN
}

\author{
(TELÉFONOS MÓVILES: HÁBITOS LECTORES Y EXCESO DE USO. UN \\ ESTUDIO CUALITATIVO EN DINAMARCA, LITUANIA Y ESPAÑA)
}

\author{
Valeria Levratto \\ Universidad Rey Juan Carlos \\ Andrius Suminas \\ Vilnius University, Lithuania \\ Theresa Schilhab
}

Danish School of Education, Aarhus University

Gertrud Esbensen

Danish School of Education, Aarhus University, Denmark

DOI: 10.5944/educXX1.28321

\section{How to reference this article/Cómo referenciar este artículo:}

Levratto, V., Suminas, A., Schilhab, T., \& Esbensen, G., (2021). Smartphones: reading habits and overuse. A qualitative study in Denmark, Lithuania and Spain. Educación XX1, 24(2), 167-188. https://doi.org/10.5944/educXX1.28321

Levratto, V., Suminas, A., Schilhab, T., y Esbensen, G., (2021). Teléfonos móviles: hábitos lectores y exceso de uso. Un estudio cualitativo en Dinamarca, Lituania y España. Educación XX1, 24(2), 167-188. https://doi.org/10.5944/educXX1.28321

\begin{abstract}
Recently, the smartphone has become the key device in families and workplaces, changing people's habits and ways of interaction in our liquid and hyperconnected societies. Little research has been done on the use of smartphones for reading, since the telephone was not associated with reading until very recently. This paper presents an overview of digital mobile reading in the digital literacy context and tries to answer different research questions, such as: how do people read on the smartphone? Do people have an addiction to/misuse of mobiles? Its objective is to offer empirical data about people's experiences of digital mobile reading and to analyse how we depend on our smartphone through a small-scale qualitative study including
\end{abstract}


different informants from three European capital cities: Copenhagen (Denmark), Madrid (Spain) and Vilnius (Lithuania).

The paper does not aim to generalise its findings, but to advance the field of digital literacy research, a field in which the meaning (the interviews) has been interpreted in relation to a wider socio-cultural context. The results report that the "context", the "time" and the "situation" where reading is carried out are decisive for understanding; furthermore, the type of navigation that readers can perform on the smartphone has important consequences in the reading process, hence, the layout must be well designed for active and attentive users on mobile devices. Our Informants assert that situations like boredom, waiting or loneliness can induce the use of the smartphone. Therefore, more research is needed, in different areas and with new digital literacy programmes in order to help young people (and adults) use their mobiles as advantageously as possible.

\section{KEY WORDS}

Reading, smartphones, mobile technology, digital literacy, hypertext

\section{RESUMEN}

En los últimos años, los smartphones han pasado a ser los dispositivos fundamentales en las familias y en los sitios de trabajo, cambiando los hábitos de las personas y las formas de interacción en nuestra sociedad liquida e hiperconectada. Aún es escasa la investigación sobre la lectura en teléfonos móviles, ya que hasta hace muy poco el teléfono no se asociaba con este hábito. Este artículo presenta una mirada sobre la lectura digital en móviles dentro del contexto de alfabetización mediática y procura contestar a diferentes preguntas de investigación como: ¿Cómo leen las personas en los smartphones?, ¿Las personas tienen adicción o abusan de los móviles?; su objetivo es ofrecer una fotografía sobre la lectura digital en estos dispositivos y analizar cómo dependemos de ellos a través de un estudio cualitativo que incluyó entrevistados de tres diferentes capitales europeas: Copenhague (Dinamarca), Madrid (España) and Vilnius (Lituania).El artículo no pretende generalizar sus resultados, sino avanzar en el campo de la investigación en alfabetización digital, donde los significados (entrevistas) se han interpretado en relación con un contexto socio-cultural más amplio. Los resultados evidencian que el "contexto", el "tiempo", y la "situación" en los que se realiza la lectura son decisivos por la comprensión, además el tipo de navegación que los lectores realizan en los móviles tiene consecuencias importantes en el proceso lector, para ello el diseño de la página debe ser bien realizado. 
Los entrevistados informan que situaciones como el aburrimiento, la espera o la soledad pueden inducir al uso del smartphone. Más investigación en diferentes áreas y con nuevos programas de alfabetización digital, sería necesaria, para poder ayudar a las personas a utilizar sus móviles de la forma más ventajosa posible.

\section{PALABRAS CLAVE} hipertexto

Lectura, smartphone, nuevas tecnologías, alfabetización digital,

\section{INTRODUCTION}

In the last two decades, the smartphone has become the key device in families and workplaces, changing people's habits and ways of interaction in our liquid and hyperconnected societies. For most people, holding their smartphone is both the first and the last gesture of their day: "The mobile is already controlled by habit, not by necessity" (Oulasvirta et al., 2012, p.108). The data are clear: in $2019,69 \%$ of mobile users in the world said they looked at their mobile in the first five minutes after waking up, and they spent an average of 194 minutes a day using their device. (Ditrendia, 2019). Little research has been done on the use of smartphones for reading since the telephone was not associated with reading until very recently. This paper presents an overview of digital mobile reading through a qualitative study including different nationalities, a significant factor when habits are analysed, taking into consideration the different cultures and how they can determine the society's identity. The framework of this paper is digital literacy; UNESCO (2018) defines various digital literacy competencies, including "Interacting through digital technologies" and "Protecting health and well-being", and the issues of reading habits and overuse that we deal with in this paper can be understood as a part of these competencies.

If the traditional reading system of the book is compared to the new reading system of the digital environment, we can observe how reading habits have been deeply modified due to the structure of the different devices. The addiction (or intense use) of the smartphone is a new factor that contributes to articulating the new complex reading context; addiction, not to the reading habits, but to the digital device as media of the infinitive opportunities.

The omnipresence and ubiquity of mobile phones are influencing the future of our culture and the relationship we have with reading: "Reading is a historically and culturally contingent practice. It has taken centuries for our 
current textual literacy to evolve. That is to say that the social significance of reading is culturally dependent." (Mangen and Van Der Well, 2016, p.4). In digital society, access to knowledge is easier and more democratic, and also faster, which leads to acceleration in different ways, as consumers of increasingly short movies, videos and stories and as producers of "short moments of life" because we are constantly distracted and interrupted by notifications, mobile tones, television announcements and the time we could dedicate to just one thing is diminished. In the digital age, text is undergoing cognitive, creative, and structural transformations, each of which causes mutations in the reading process' in both time and space. As a consequence, in the network society (Castells, 2004) the concept of reading is blurred, modified and the "physical space of the virtual" has a leading role (Schilhab et al., 2018). The location where reading takes place is also "read" because: "reading is a physical, multisensory engagement with a device" (Mangen and Van der Well, 2016, p.6). Accordingly, reading is no longer just a cognitive process, as it has long been considered, but a more complex phenomenon encompassing all our senses, and with a direct relationship with space, especially if it is carried out on a smartphone: "Our physical reading environment is much more than a potential source of distraction; it can scaffold our mental imagery and understanding of a text by offering congruent perceptual stimuli" (Balling, et al., 2019, p.7).

In this new reading ecosystem, to understand a digital text we no longer have to immerse ourselves only in the written text; we also need to have reading skills that allow us to identify: the different formats in which information is presented, the constantly growing number of available information sources and the varying quality of the information available (Salmerón, et al., 2018). If the word is the skeleton of the book, we can deduce that hypertext is the skeleton of the digital text, where different languages converge in a single space and where the act of "perception" plays a fundamental role: "Digital reading devices extend the act of reading beyond not only the audio-visual field of perception, but also the field of perception and cognition altogether, to requiring physical and ergonomic interaction with the devices in different ways compared with printed media" (Mangen and Schilhab, 2012, p.7). It is therefore important to analyse the reading process in front of a screen considering the different elements that constitute its texts/ hypertexts and all the cognitive, ergonomic, and haptic factors that it involves.

\section{READING HABITS}

Our reading habits are changing. Libraries are no longer used as much as before and, while virtual visits to their web pages are increasing (Lee, 
2018) libraries are losing many readers with the paradoxical inflation of new books. Reading no longer involves physically going from one place to another or interacting with others in public spaces; rather, it is reduced to an individual's experience in isolation through a screen, even so, we still should include in the reading process the relationship between the artist and the reader, according to Eco's idea of "open work": the author's decision to leave arrangements of some constituents of a work to the public.

Furthermore, the sales of books (in paper or digital format) on platforms, such as Amazon and Google are increasing. Thanks to the format of the e-book, many people choose to read on mobile devices. The places where we interact with our mobile devices vary greatly and it is not even necessary to be in an area with internet reception to read the news, since it can be downloaded both in text and audio format.

The new reading practices imply profound changes in the development of analytical thinking through reading a printed text. The deep reading practices that we had come to take for granted after centuries of book culture are supposedly being replaced by shallower forms of reading (Mangen et al. 2016). Many researchers (Morozov, 2012; Bauman, 2015) draw our attention to what we are losing by moving away from the reading of written texts. As Wolf asserts: "On-screen texts are not read -inferentially, analytically and critically-; they are skimmed and filleted, cherry-picked for half-grasped truths. By doing this we risk losing the 'associative dimension' of reading, those precious moments when you venture beyond the words of a text and glimpse new intellectual horizons" (2008, p.48). The practices and habits of reading are currently moving into the infinite possibilities offered by digital devices. Thanks to Information and Communications Technology (ICT), we can benefit from individualized, personal and multimodal reading itineraries through different pieces of knowledge that we reconstruct thanks to our previous knowledge, culture and psychological moment, in line with the connectivity described by Siemens (2005) and Downes (2010), and with the idea of Afflerbach and Cho (2009) that readers also become the "authors" of an integrated mental representation by selecting and integrating different pieces of information.

In the network society, looking at Facebook updates or listening to WhatsApp voice messages can for some people go beyond a simple habit and get closer to addictive behaviour. In this argument we subscribe to Starcevic's definition of Addiction as "Any pleasurable activity performed in excess and having some negative consequences (2013). Until recently, we had in our hands a device that only allowed us to make calls; now, we have an "omniscient machine", and intense mobile usage could become a compulsive and addictive disorder which "looks set to become one of the 
biggest non-drug addictions in the 21st century" (Mobile phones becoming a major addiction, 2003) unless we actively make strategies for which role we want our smartphones to play in our lives. Many studies have identified as "addictive" the behaviour of people who have a dependence on mobile phones (Hooper and Zhou, 2007), the Internet (Young, 1998) or online video games (Markey and Ferguson, 2017), although these do not necessarily have to lead to a pathology. Internet-related disorders are often a matter of compulsive use which doesn't reach the level of a true psychological, social or physical health issue, per se (Chakraborty, 2017). The addictive use of mobile devices could therefore be considered more as a "misuse" than as an addiction (Panova and Carbonell, 2018).

The challenging relationship between a device that has become one of the main media for reading and at the same time is potentially addictive raises a variety of questions; these questions have guided this work.

\section{RESEARCH DESIGN}

The research questions of the project were: How do people read on the smartphone? What reading strategies do they use? In which environment do they use smartphones the most? Do people have an addiction to/misuse of mobiles?

In attempting to answer the research questions, we opted for an exploratory study with a qualitative interview approach (Brinkmann, 2013) focused on making our informants share their experiences with mobile reading. The aims of the project were: to make a small comparative study between Denmark, Lithuania and Spain about reading strategies on smartphones; and to analyse how we depend on our smartphone (intense use or addiction). Using qualitative studies, we do not aim to generalize statistically, but rather to employ some form of analytic generalization (ibíd).

The research design and the interview guide were designed in a meeting in Copenhagen in 2017 and the open and semi-structured interviews were carried out in 2017-2018.

The study consists of 15 interviews with 5 informants from each country ( 8 males and 7 females). The interviews were semi-structured and lasted from 30 minutes to 120 minutes. They were conducted in Danish, Lithuanian and Spanish, recorded and subsequently transcribed and translated to English. Afterwards, the authors held a two-day data analysis workshop in Copenhagen where all the interviews were read aloud in order to identify categories, and different topics were discussed by the research team. 

LITHUANIA AND SPAIN

Selection criteria: The informants had to have a maximum of 3-4 years of university study and be aged between 35 and 50 years old, which means young digital students are not included in the sample. The goal was to include adults who are quite active in digital environments but who were not born with new technologies. The informants were proficient active smartphone users who, read on their mobiles several times per week. They also had at least one account on a social network, and were able to make online purchases (for example, movie or bus tickets).

Informants were recruited by recommendations and by the snowballing method. Interviews were conducted in the homes of the interviewers or the informants, or at their workplace. We recorded the interviews on different devices (tablets, smartphones, etc.) and we took contemporaneous notes (about the feelings, emotions or body language of the informants in order to offer more qualitative perspective). After transcription, the names of the informants were changed: the informants' names starting with " $D$ " refer to Danish informants, with "L" to Lithuanians' and with "S" to Spaniards.

In attempting to answer the research question, we designed an interview guide covering four topics: a) Basic phone-related questions (e.g. When do you use your phone for information seeking? b) Personal phone habits (e.g. What do you do when you need to relax? -Do you sometimes choose to turn off your phone?) c)Sharing text (e.g. If you receive a notification from a social network do you leave the page you are reading to follow the notification? While you are reading do you share information on social networks?); d) Other people's phone habits (e.g. Do you get annoyed/offended by other people's use of their phone? In what situations?). The questions were open or semi-structured so informants could express their feelings and perspectives freely.

In this paper, we focus on topics "a" and "b", but due to the qualitative approach of the project, other topics where also considered. They will be explained in future papers.

Considering the nature of this study, where the respective cultures of the informants often come into play, we were required to interpret their points of view and thoughts with a qualitative approach and by choosing informants from three different European countries, we aim at filling the need for studies in the area of mobile devices that include people of different nationalities in their sample (Hooper and Zhou, 2007). We can observe differences in the three countries selected: Denmark, Spain and Lithuania, with 47.50, 25.00, and 13.13 euro GDP per capita, respectively, (Eurostat, 2018) which represent a high, medium and low pro-capita income level in the European economic context. As for rates of mobile internet use: Denmark has $88 \%$, Spain has $80 \%$ and Lithuania has $62 \%$, (aged 16 to 74 ), (ibid.). 


\section{RESULTS}

The categories we created to analyse the interviews were: Patterns of book reading on smartphones; Pleasure in reading habits; How mobile size influences readers; Use of links; The need to look at the smartphone "as soon as I can".

\section{Patterns of book reading on smartphones}

Informants from all of the countries generally report that the digital experience is much faster or more chaotic, and therefore less deep than reading on paper. They also prefer to print text rather than read on digital devices and send documents from smartphones to a PC for printing (e.g., long e-mail or PDFs). They emphasize the need to physically mark, underline or highlight sections of text, which they can do only on paper. The Informants offer many examples:

I see everything on my mobile, but I would never read a book on my mobile. If someone sends me a PDF text to my mobile, I send it to the computer and I print it, because I need to underline... for me paper is much better. (Sebastian, Spain)

Many informants' need to print PDFs or long texts is due in part to the fatigue induced by the screen, and partly to the discomfort of reading on small devices. In effect, the medium determines the type of reading they want to perform. When reading on a digital device, most of them skip all of the introductory parts and go directly to the key points. They often report that on their smartphones they skim more than they read and they tend to repeat the same reading pattern.

This informant explains his ways of reading based on the objectives that he set:

I always read from the top to the bottom if the text is very interesting. Then if I have to do a search, for example, I put what I want to search for in Google and I open six pages. Then I go through the six pages very quickly. I also do a visual search for what I want to find. (Sebastian, Spain)

Reading patterns from printed text influence Sebastian's reading habits on mobile devices -from top to bottom- while Dagmar finds just the opposite: the digital medium influences her way of reading a printed text. As she explains: 
Yeah, I don't really know... I think, when I have the papers, I'll start skim-reading right away, while I read it more thoroughly when it's on a screen, in some way without really knowing why. I don't know! [Laughs] (Dagmar, Denmark).

When talking about "reading" on a smartphone, it is important to reflect on the complexity of the hypertexts on web pages, because they can make reading difficult if navigation is not clear to the user: "Hyperlinked structure may be particularly challenging to navigate if it's not visible to the reader and if they overload their processing capacities". (Salmerón et al., p.98). It is worth highlighting the importance of having some consistency between the design of web sites created for computers or smartphones, as this informant explains when she answers a question about where she prefers to buy a train ticket or tickets for a concert:

From the beginning I used the page to buy stuff on line on the laptop, then when I went to the mobile, I saw areas of the web that were not on the mobile or I could not find them. It did not seem intuitive. (Sabrina, Spain)

To read on websites and understand the steps to be taken, it is essential that the page has a clear structure. From a design perspective, one way to prevent comprehension problems is "to provide navigation guidance such as organizational overviews" (ibid), like the navigation maps that many websites show on their home page. As one informant explains:

The designers didn't have the right knowledge about media design and font use, and these kinds of things... Well, I have to say that something like Ekstrabladet [a Danish newspaper] with their flashy news, it's easy to read on the phone because there are short spots you just read and so on to the next. (Dan, Denmark)

In summary, we can observe that different ways of reading are hybridized in mobile environments: they mix the ways of navigating in hypertexts with the ways of reading a printed text. There is also a need to print long texts, either because of the need to give corporality to reading or because of the visibility issues that small devices can present.

\section{Pleasure in reading habits}

Our informants mention that they would not sit down with their smartphone to start reading for pleasure as they would with a book. In some cases, they seem to feel that the smartphone wouldn't be able to create a learning environment. As Schilhab et al say: "the act of reading becomes 
connected to what the body is doing while reading thus influencing what (and how well) we remember the text we are reading" (2018).

Other informants refer about how they use their smartphone to relax for short periods of time while they scroll through their social network feeds.

This Spanish informant is very explicit when he indicates what he needs for "Reading":

When I have some extra time or I have come home early and I lie down comfortably... then I say "now it's worth it to read" (...) I think most of my reading on the smartphone happens in two ways. The first one is: lying down at home (...) The second way of reading on my smartphone is on public transport, where I must stand or on the subway platform while waiting. (Sergio, Spain)

This informant from Denmark highlights the formality of the act of reading, preferably on paper, which he associates with a "sitting moment":

On the phone I have another relationship to the text. It may very well, sort of, say, go into my eye and out of my ear, or how do you say it. But if I sit down with a piece of paper..., it's more official in some way. If anyone has taken the trouble to print it down on paper, then there is probably a purpose with it. And then when I'm going to read it, I'd like to understand it, too... (Dan, Denmark)

As those informants explain and as was found out in previous research (Burke and Bon, in Balling et al., 2019), traditional reading locations such as the bed or couch are still much preferred.

Another informant feels that we learn more when reading on paper:

I believe more information is acquired from a paper (Lithuania, Laura).

\section{How mobile size influences readers}

The size of the mobile certainly influences reading. If the text is short, informants report that they read on their smartphone, but for long texts they prefer a bigger screen or paper. Multimedia material can also be watched better on a bigger screen. They say that they prefer to read narrative texts on another device or paper. The "font" is partly to blame for the poor reading experience on the smartphone and some informants 
are annoyed by scrolling up and down to finish an article. As one Danish informant asserts:

The font, I think... I get so tired of sitting there and enlarging it and scrolling: with news it's fine, because you click and you can read a bit. But if I had to do it longer, like, with more text, then I'd be tired of moving it back and forth all the time. (Dicte, Denmark)

This Lithuanian informant also reports the same thing, concluding that the larger the available space, the better the reading:

I need a big screen, as big as possible. $8 / 9$ out of 10 . It is part of my personal life. (Lukas, Lithuania)

All these informants have stated that they have normal vision (they don't use glasses for reading), so their preference for larger screens is not due to vision problems, as one might think.

The smartphone is good for reading short texts, especially news or social media. Some informants claimed that they have lost the habit of reading book and have replaced it with surfing on the smartphone, as this Spanish woman asserts:

Once, for example, before sleeping, I could spend hours with my book. Now, before sleeping, I take my mobile and I just spend time gossiping on Facebook (...). The truth is that when I had to go to school and I had to take the bus I always had a book in my bag... I read every day, and now... you know what I read? Nothing! I hardly read paper books anymore... (Sara, Spain)

We are aware of the "loss" of book and reading, but are we gaining something else in exchange? Do we have more social relationships, or more time for friends and family, even if our interactions are virtual?

\section{Use of links}

Links represent an important "gateway" to new content which allows us to expand on the information we are reading. On the other hand, links can also create conflicts as we form a mental map of what we are reading, essential every time we read. When reading on the web, an important task is to identify and select the information that should be included in the process of constructing an integrated representation of the material (Salmerón et al., 2018, p.98). According to this study, readers adopt a variety of strategies when facing a text with many hyperlinks. Some informants report that after 
visiting a link, they go back to the main page, because they need to complete what they were reading. They say that they use links like the footnotes in printed texts, easily going back and forth between the notes and the main text so as not to get lost.

\section{This informant is very clear when explaining his strategy with links:}

If I click on a link, I usually see what's on the new page. Then I take a quick look and then return to the original, I must say that I always go back... I have a bit of an obsession to go back. It is as if I always had a red light that says "come back, come back" and this same light tells me "Maybe when you finish the article you will see some other links, but now you have to finish this". When I read on paper if I see the numbers or the asterisks of the footnotes or endnotes, they physically bother me a lot. So, I leave a finger where I was reading, to read the note but then, I need to find my place again... And I apply this same thing to the mobile phone. (Sergio, Spain)

The need to not get lost has to do with high semantic coherence: "Most readers may decide to select hyperlinks to try to maintain a high level of semantic coherence between the currently read section and the linked page, avoiding the big 'semantic jumps' between pages that often occur when interest drives navigation". (ibid p.93)

Nevertheless, other informants have commented on something different regarding links. For example, Dagmar said the following about her use of links in Wikipedia articles:

Yeah. That depends on what it is, but I use the links. I won't always read the whole thing first (...), you don't always know if it's the right thing you're reading, and then I'll check if someone else has written something, about a person or something. And then what shows up when I Google it. (Dagmar, Denmark)

Usually, when reading hypertext (text, image and audio), informants explained that they tend to read the text and then see the images or videos afterwards. One reason for this could be that "the integration of words and images is a quite demanding process requiring efficient use of cognitive capacity" (ibid p.99). In a hypertext we have different languages that converge and require different reading and comprehension strategies.

It should be said that what users do most from their mobile is watch videos $(42 \%)$ followed by browsing the Internet and using social networks (Ditrendia, 2019); reading as such is not among these priorities. 


\section{The need to look at the smartphone "as soon as I can"}

Researchers have not reached a consensus on whether an excessive use of mobile phones can be called an addiction, because there is a lack of longitudinal studies to confirm the stability of the disorder (Panova and Carbonell, 2018). Even when people report that they can't stand to be separated from their mobile phones at any time of the day, we have to consider how expensive these devices can be, the amount of important information they may contain and the fear that they will fall into the wrong hands (ibid).

In fact, many of the informants use the term "addiction" when referring to their relationship with their mobile and report that this device is becoming a problem in their life. Surrat (in Panova and Carbonell, 2018, p.6) has explained how the limited understanding of new information and communication technologies "is often taken advantage of by the media who capitalize on the suspicion that accompanies new technological developments and publish sensationalist news stories about addictions and psychopathology, which contribute to the social construction of a pathology" .Therefore, more scientific data is needed in order to understand exactly how this device is changing our lives.

Many of our informants emphasized their "addiction" to their mobile:

I do not think four minutes go by without me looking at my mobile. And the truth is that it scares me. I would look at my phone out of inertia. (Samuel, Spain)

This Danish woman also uses the term "addiction" to refer to physiological issues:

But I just think it's a habit or something that makes you want it. It's not like I'm posting myself and liking and stuff like that. That's not what pulls me in at all because I don't use it like that. It's the curiosity about what's going on. And I'm very aware of that and that it's actually quite stupid. But um (laughs) there's something in the body or the brain, I think, that makes you addicted. (Dicte, Denmark)

Many informants are aware of the need to find solutions for this addiction or misuse:

I think it's something that happens automatically, but then again, I become aware of it the minute I pick it up and start using it, why am I even doing this, because I did it five minutes ago? Why am I doing it again? And if 
I don't actually have an immediate need for it, maybe just put it away again, right, because I'm just thinking that it's actually a bit stupid that I'm using it. (Dyveke, Denmark)

Different issues could influence feelings of dependency towards the mobile: being bored (for example, at work), being unemployed, or being single; hence, the context where we use smartphones is crucial to understanding the subject's relationship with the device. The problems arising from smartphone use are dependent on what activities the user engages in while on the smartphone and the motivations for engaging in these activities (Jeong et al., 2016).

In general, it is difficult to determine whether or not the dependence is created by a boring or less stimulating context, such as an unrewarding job, as this Spanish informant reports:

I do not like my job so much. The phone is an escape. I am entertained by seeing a picture of a friend or some video... The truth is that if I feel happy and satisfied, I do not look at it. (Samuel, Spain)

It does not have to be just a boring situation; it may even be that a person needs to kill time (in a supermarket queue, on public transport, etc). Therefore, we observe that both WhatsApp and Facebook often provide a way to simply "spend time with the mobile". The screen is the space of easy and readily available stimuli, capable of filling certain moments of loneliness. This is what Sabrina says:

Recently I decided to stop filling my dead time with things from the mobile device...We have this concept that we want to make the most of our time, this idea of being super optimal when doing something. (Sabrina, Spain)

If we use our smartphones to read during these sporadic moments of free time we are at a significant disadvantage, since, paper-based reading has been shown to have advantages when reading time is limited, as compared to during self-paced reading. (Delgado et al. 2018, p.12)

Returning to the different issues that could be at play when users feel dependent on their mobile, we observe how having a partner and making plans with him or her can replace contacts on social networks. As this informant asserts:

I used to be very addicted to Facebook. I needed to see what people did, photos and gossip... And then there was an excess of information and... 

LITHUANIA AND SPAIN

I changed my status from being a single man to having a partner... and it changed a lot. My social life changed a lot... (Samuel, Spain)

Having or not having a job also influences the amount of time spent in front of WhatsApp:

And of course, it changes a lot if I'm unemployed or if I'm working... If I am unemployed, I read WhatsApp, but I read more other things. (Sergio, Spain)

Therefore, it can be observed that in many cases, the use or abuse of smartphones does not depend so much on a person's will power, but rather on their social, professional or academic situation (Panova and Carbonell, 2018). Indeed, before the advent of mobile phones, in how many circumstances did we feel bored or overwhelmed and loved being able to open a newspaper to distract us? How many times have we been in a work meeting forced to listen and eager to evade with our book? At present, we can do that since the mobile's screen is a shield defending us: it's seems to offer a properly justification for different contexts.

\section{DISCUSSION}

Overall, for our informants, reading in the sense of "deep reading" on a mobile phone is not comfortable, because of the size of the device and because they find paper more pleasant. In fact, we found that many of them still print digital texts and even e-mails, and they report a feeling of lower comprehension on digital devices. Other recent research has revealed how "digital environments may not always be best suited to fostering deep comprehension and learning" (Delgado et al., 2018, p.11), and that "people adopt a shallower processing style in digital environments" (Lauterman and Ackerman, 2014).

For our informants, the "context", the "time" and the "situation" where reading is carried out are decisive for understanding, which is consistent with the idea of Mangen et al. (2016) that reading is a "multidimensional" act and influenced by many factors. There are currently different "hybridations" (Canclini, 1990) in reading on different media and devices, with distinct profiles of readers who mix the modalities differently, as our informants have explained.

The type of navigation that readers can perform on the smartphone has important consequences in the reading process. Our informants reported having trouble using their smartphone to view websites designed 
for computers or laptops. When a page is designed for the smartphone, its architecture is clearer to users and they do not experience the bothersome feeling of being lost. The layout must be well designed for active and attentive users on mobile devices. Web browsing has traditionally been studied as a process "distinct from comprehension of a single text, however, because it is considered to play a particularly important role in hyperlinked digital environments" (Cho, 2014; Leu et al., 2015).

It remains to be seen whether a new term will be adopted to define reading in virtual environments in addition to the many terms that have already been used, such as grazing, browsing, hunting, surfing and scanning. Or perhaps, the term "reading" should be extended to include new practices. In the history of reading, rigid, professional and organized book use practices have always been contrasted with free, independent and unregulated practices (Cavallo and Chartier, 1997), so it may not be a problem that arises only from digital ecosystems.

Regarding the misuse or intense use of smartphones, in general, a greater dependence on mobile devices is mentioned among Spanish informants compared with the northern Europeans analysed in this study. More specifically, an overuse of WhatsApp stands out, in the Spanish case, followed by Facebook. In Denmark and Lithuania, on the other hand, Messenger and Snapchat are the most popular, according to our informants. This alleged abuse of WhatsApp in a society as open as Spain is thought to be connected to a sociological reflection. Some studies (Ito, 2005) have shown that the cultural norms of some countries in Asia make it difficult for people to socialize freely and spontaneously, which may contribute to the intense use of the smartphone in that part of the world. But can this be said about Spanish society? Maybe it's just the other side of the story: a society that is already very open and sociable reflects its social behaviours and norms on its screens. In addition, it is also important to highlight that technology and the use of it is deeply entangled with societal structures, discourses, and social practices.

Considering the qualitative nature of this study, what can be asserted is the awareness of the Spanish informants of their intense use or addiction to WhatsApp and of the need to solve this problem. Even the problem of sleep emerges in the interviews since, as with any other dependency or addiction, abuse of a device can condition our life: "Compulsive Facebook use has also been shown to disrupt sleep. People scoring high on Facebook addiction scales report delayed bedtimes and rise times on both weekdays and weekends compared with people with lower Facebook addiction scores" (Chakraborty, 2017, p.9). 
Overall, the changes in lifestyle related to the mobile are very present in all the interviews: all, to a greater or lesser extent, report that society has changed, and it is not very clear how to deal with the overuse of mobiles and with the constant messages received. Many yearn for face-to-face relationships to continue to play an important role in our lives: "I think that with so many mobiles we are losing the charm of our relationships a bit" (Sabrina, Spain). Some informants reported that the mere sight of their smartphone can bother them in some circumstances, for example, when they want to relax or unwind. On this matter, some research (Ward et al., 2017) has shown how the mere presence of one's own smartphone "may induce brain drain" by occupying limited cognitive resources for purposes of attentional control. It would be important to consider these results, especially when activities that require greater cognitive capacity are being carried out, for example, in educational contexts.

Another consideration that comes up from our informants is "the context" in which mobile addiction is described: Situations like boredom, waiting or loneliness can induce the use of the smartphone. Previous research has shown that "behaviour type could also differ according to situation and environmental conditions" (Hooper and Zhou 2007, p.283). Situation and context can also generate addictive, compulsive, dependent, habitual and mandatory (ibid.) users, despite their desire not to use the device.

\section{CONCLUSIONS}

Our informants offer interesting perspectives about reading habits and overuse of smartphones in a digital literacy framework, and many of them voiced the same opinions on a number of topics.

Many informants agreed that our relationship with smartphones is unhealthy, and that habits common before the advent of the smartphone (such as reading on paper before sleeping) should be revived. The informants also agreed on the fatigue and disorientation caused by reading on mobile phones, in accordance with Delgado et al. findings about digital reading: "scrolling (...) may add a cognitive load to the reading task by making spatial orientation to the text more difficult for readers than learning from printed text" (2018, p13). Healthy habits seem to be yearned for by the informants.

Thus, we can observe that different ways of moving through texts on paper or digital devices - characterize the reader of the digital age. Therefore, in a learning context, attention to the different dimensions of the reading process, such as the ergonomic, attentional, perceptual, cognitive, emotional, phenomenological, sociocultural and cultural (Mangen and Van 
der Weel, 2016) will be helpful in understanding the relationship between readers and devices. These different perspectives will in turn help us to understand what kinds of thinking and learning are fostered through reading in digital environments.

Hence, it will be important to have more elements to create curricula that take into account precisely when it will be beneficial to introduce the smartphone in the classroom, and when it will be important to continue reading a traditional book. Educational communities must hybridize and know how to take advantage of different types of reading on different devices. For example, the interviews show that social networks are the privileged space of the smartphone and that for short texts or videos, this device is very practical, this type of reading generally being of a more recreational nature.

Therefore, more research is needed in different areas and with new digital literacy programmes in order to help young people (and adults) use their mobiles as advantageously as possible.

Some data present in this paper are included in other papers by the same authors

\section{ACKNOWLEDGEMENTS}

This article is based upon work from COST Action IS1404 E-READ (Evolution of Reading in the Age of Digitisation), supported by COST (European Cooperation in Science and Technology). 


\section{REFERENCES}

Afflerbach, P., \& Cho, B. (2009). Determining and describing reading strategies: Internet and traditional forms of reading. In H.S. Waters \& W. Schneider, Metacognition, strategy use, and instruction (pp. 201-225). Guilford Press.

Balling, G., Begnum, A., C Kuzmičová, A., \& Schilhab, T. (2019). The young read in new places, the older read on new devices: A survey of digital reading practices among librarians and Information Science students in Denmark. Participations, Journal of Audience \& Reception Studies, 16(1), 197-236.

Bauman, Z. (2012). On education. Polity.

Brinkmann, S. (2013). Qualitative interviewing. Oxford University Press.

Carr, N. (2018). The shallows: What the Internet is doing to our brains. W.W. Norton \&Company.

Canclini, G. N. (1990). Hybrid cultures. Strategies for entering and leaving modernity. Grijalbo.

Castells, M. (2004). La sociedad red: una visión global. Alianza.

Cavallo, G., \& Chartier, R. (2011). History reading of the occidental world. Taurus.

Chakraborty, M. D. (2017). Facebook Addiction: An Emerging Problem. The American journal of Psychiatry, 11(12), 7-9,

Cho, B.Y. (2014). Competent adolescent readers' use of Internet reading strategies: A think-aloud study. Cognition and Instruction, 32, 252-289.

Delgado, P., Vargasb, C., Ackermans, R., \& Salmerón, L. (2018). Don't throw away your printed books: A meta- analysis on the effects of reading media on reading comprehension. Educational Research Review, 25, 23-38 https://doi.org/10.1016/j. edurev.2018.09.003

Ditrendia (2019). Informe Mobile en España y en Mundo 2019. https://cutt. $\mathrm{ly} / \mathrm{JzbfwAG}$

Downes, S. (2010). New technology supporting informal learning. Journal of Emerging Technologies in Web Intelligence, 2(1), 27-33.

Hooper, V., \& Zhou, Y. (2007). Addictive, dependent, compulsive? A study of mobile phone usage. BLED 2007 Proceedings, 38. https://cutt.ly/OfJHXpZ

Ito, M. (2005). Mobile phones, Japanese youth, and the re-placement of social contact. In R. Ling \& P. Pedersen (Eds.), Mobile communications: Renegotiation of the social sphere (pp. 131-148). Springer.

Jeong, S. H., Kim. H., Yum, J. Y., \& Hwang, Y. (2016). What type of content are smartphone users addicted to? SNS vs. games. Computers in Human Behavior, 54, 10-17. https:// doi.org/10.1016/j.chb.2015.07.035

Lauterman, T., \& Ackerman, R. (2014). Overcoming screen inferiority in learning and calibration. Computers in Human Behavior, 35, 455-463. https:// doi.org/10.1016/j.chb.2014.02.046

Lee, A. (2018) Physical and digital reading habits of adult Singaporeans, Journal of Library Administration, 58(6), 629-643. https://doi.org/10.1080 /01930826.2018.1491189

Leu, D.J., Forzani, E., Rhoads, C., Maykel, C., Kennedy, C., \& Timbrell, N. (2015). The new literacies of online research and comprehension: 
Rethinking the reading achievement gap. Reading Research Quarterly, 50, 37-59. https://doi.org/10.1002/rrq.85

Mangen, A., \& Schillhab, Y. (2012). An embodied view of reading: Theoretical considerations, empirical findings, and educational implications. In S, Matre \& A. Skaftun (Eds.), Skriv! Les! Akademika forlag

Mangen, A., \& Van Dick, A. (2016). The evolution of reading in the age of digitisation: an integrative framework for reading research. Literacy, 50(3), 116-124. https://doi.org/10.1111/ lit. 12086

Markey, P. M., \& Ferguson, C. J. (2017). Internet Gaming Addiction: Disorder or Moral Panic? The American Journal of Psychiatry, 173(3), 195196. https://doi.org/10.1176/appi. ajp.2016.16121341

Mobile phones becoming a major addiction (2003). https://cutt.ly/ lfHf6Uf

Morozov, E. (2012). The disappointment of the Internet: The myths of freedom on the web. Imago Mundi.

Oulasvirta, A., Rattenbury, T., \& Raita, E. (2012). Habits make smartphone use more pervasive. Personal and Ubiquitous Computing, 16(1), 105114.

Panova, T., \& Carbonell, X. (2018). Is smartphone addiction really an addiction? Journal of Behavioral Addictions, 7(2), 252-259. https://doi. org/10.1556/2006.7.2018.49

Schilhab, T., Balling, G., \& Kuzmicova, A. (2018) Decreasing materiality from print to screen reading. First Monday, 23(10). https://doi.org/10.5210/ fm.v23i10.9435

Siemens, G. (2005). Connectivism: A learning theory for the digital age. International Journal of Instructional Technology and Distance Learning, 2(1), 3-10. http://www.itdl.org/Journal/ Jan_05/article01.htm

Starcevic, V. (2013). Is Internet Addiction a Useful Concept? Australian \& New Zealand Journal of Psychiatry, 47(1), 16-19.

Salmerón, L., Strømsø, H. I., Kammerer, Y., Stadtler, M., \& Van den Broek, P. (2018). Comprehension processes in digital reading. In M. Barzillai J, Thomson S, Schroeder, \& P. van den Broek (Eds.), Learning to read in a digital world (pp. 91-120). John Benjamin.

UNESCO (2018). A global framework of reference on digital literacy skills for Indicator 4.4.2. UNESCO. https://bit. ly/38ouiGA

Ward, A., Duke, K., Gneezy, A., \& Bos, M. (2017). Brain drain: The mere presence of one's own smartphone reduces available cognitive capacity. Journal of the Association for Consumer Research, 2(2), 140-154.

Wolf, M. (2008). Proust and the Squid: The story and Science of the reading brain. Harper Perennial.

Young, K. (1998). Internet addiction: the emergence of a new clinical disorder. Cyberpsychology \& behavior, 1(3), 237244. 


\section{PERFIL ACADÉMICO Y PROFESIONAL DE LOS AUTORES}

Valeria Levratto. ORCID: https://orcid.org/0000-0002-9204-4937

Phd in Communication and Education in Digital Environment from UNED University, Spain. Lecturer in Rey Juan Carlos University, Madrid, Spain. Postdoc scholarship (EuroInka Project-Manchester Metropolitan University) in San Luis' University, Argentina. Her main research areas are Digital Reading, Media Education, Digital Literacy, Digital divide. E-mail: valeria.levratto@urjc.es

Andrius Suminas. ORCID: https://orcid.org/0000-0003-0384-2011

PhD in Communication and Information from the Faculty of Communication, Vilnius University, Lithuania. Since 2015 he has held the position of Associate Professor, 2017-2020 he was a Head of Digital Media Lab at the Vilnius University. His main areas of research are interactive networking, media literacy, political communication, social media, communication theories. E-mail: andrius.suminas@ kf.vu.lt

Theresa Schilhab. ORCID: https://orcid.org/0000-0003-4204-9788

Theresa Schilhab holds a senior doctorate degree (dr. pæd.) in educational neuroscience from Aarhus University, Denmark and a Ph.D. in cognitive biology from the Niels Bohr Institute, Copenhagen, Denmark. She is Associate Professor at the Centre of Future Technology, Culture and Learning, Aarhus University. Her research centres on the relation between multimodal sensorimotor memories and abstract thought. E-mail: tsc@edu.au.dk

Gertrud Esbensen ORCID: https://orcid.org/0000-0002-9739-4127

PhD in Educational Anthropology from the Danish School of Education, Aarhus university, Copenhagen. She is a part of the research program Future Technologies, Culture and Learning as a postdoc. Her main research areas are sociocultural studies of technological literacy and what smart technology does to children and young people's nature experiences. E-mail: gle@edu.au.dk

Fecha Recepción del Artículo: 20. Septiembre. 2020

Fecha Modificación del Artículo: 06. Febrero. 2021

Fecha Aceptación del Artículo: 09. Febrero. 2021

Fecha Revisión para Publicación: 21. Febrero. 2021 
